\title{
An isolated femoral vein injury caused by bull horn
}

\author{
Hamit Serdar Başbuğ ${ }^{1}$, Hakan Göçer², Yalçın Günerhan², Kanat Özışık
}

\footnotetext{
1) Department of Cardiovascular Surgery, Kafkas University Faculty of Medicine, Assoc. Dr., Kars, Turkey

2) Department of Cardiovascular Surgery, Kafkas University Faculty of Medicine, MD, Kars, Turkey

3) Department of Cardiovascular Surgery, Kafkas University Faculty of Medicine, Prof. Dr., Kars, Turkey
}

\begin{abstract}
Animal related injuries are frequently reported in countries where the bulls are used for traditional show events like bullfighting and bull-running as well as in countries where the farming and livestock rearing is predominantly practiced. Although they are rare among other penetrating traumas, they often tend to be mortal. They have a unique pattern of injury mechanism. Bull gore injuries frequently target the perineal, abdominal and inguinal regions. An isolated femoral vein injury which is caused by an inguinal bull gore with a massive hemorrhage is unusual and it has not been reported in the available literature. In this paper, successfully treated a male patient from the villages of Kars district, who presented with an isolated femoral vein injury after bull gore was presented.
\end{abstract}

Keywords: Bull gore, femoral vein, injury. 


\section{Introduction}

Bullhorn injuries have rarely been documented in the literature. Most of the articles are related to the injuries occurred during bullfighting shows and bull-running festivals. ${ }^{[1]}$ Bullfighting is still a popular and uniquely cultural tradition of many Ibero-American countries (Spain, Portugal, Mexico etc. . ${ }^{[2]}$ Injuries of bull attack frequently occur in these countries because these animal are used in the celebrations and shows. ${ }^{[3]}$ However, animal related injuries are more frequently reported in countries where the bulls are used for farming and stockbreeding. ${ }^{[4]}$

Despite their rate is low among all injuries, bull gorings tend to be fatal. Major vascular injuries to the limbs caused by this type of penetrating traumas often involve the arteries. ${ }^{[2,5]}$ However, these vascular traumas, being either arterial or venous, need a prompt and precise intervention. ${ }^{[6]}$ Injuries and even deaths caused by bulls can also be seen in Kars province, the easternmost part of Turkey, where farming and livestock rearing are widespread practiced. An isolated injury to the femoral vein caused by an inguinal bull gore has not been reported so far in the available literature. In this article, an unusual case of an isolated femoral vein injury due to bull gore without any arterial or neurologic involvement and its successful surgical treatment are presented.

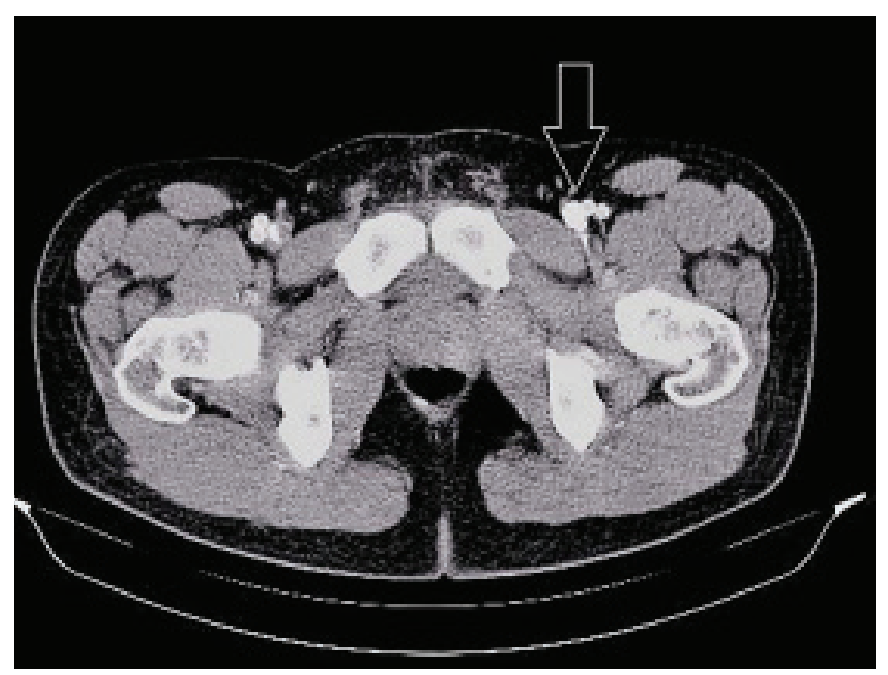

Figure 1. Computerized Tomography (CT) Angiogra phy scan. Arrow is showing the opaque extravasation out of the left common femoral vein laceration.

\section{Case Report}

A 34-year-old male referred to the emergency department after gored with the horns of a bull in his left femoral region. There was a massive bleeding from the femoral triangle with a hematoma inside the horn entry site. Palpation of the peripheral pulses revealed no pulse deficit. Color Doppler ultrasound showed triphasic patterns in all distal arterial vasculatures. He was semi-conscious due to massive blood loss with a blood pressure of 60/35 $\mathrm{mmHg}$ and a heart rate of $123 \mathrm{bpm}$.

Computerized Tomography (CT) Angiography examination was performed to determine the origin of the bleeding and vascular injury. CT Angiography scans revealed no arterial injury, but an opaque extravasation over the left femoral vein was inspected (Figure 1). That extravasation and femoral sheath opacification demonstrated the left femoral vein injury.

The patient was taken to the operating room. Under general anesthesia, the left femoral region was explored through a longitudinal skin incision. The femoral sheath was reached under the fulminant bleeding. The common femoral vein laceration was identified. Proximal and distal clamps were entrenched, and a side-clamp was positioned to secure further the vein from bleeding (Figure 2). Unfractionated heparin was given intravenously.

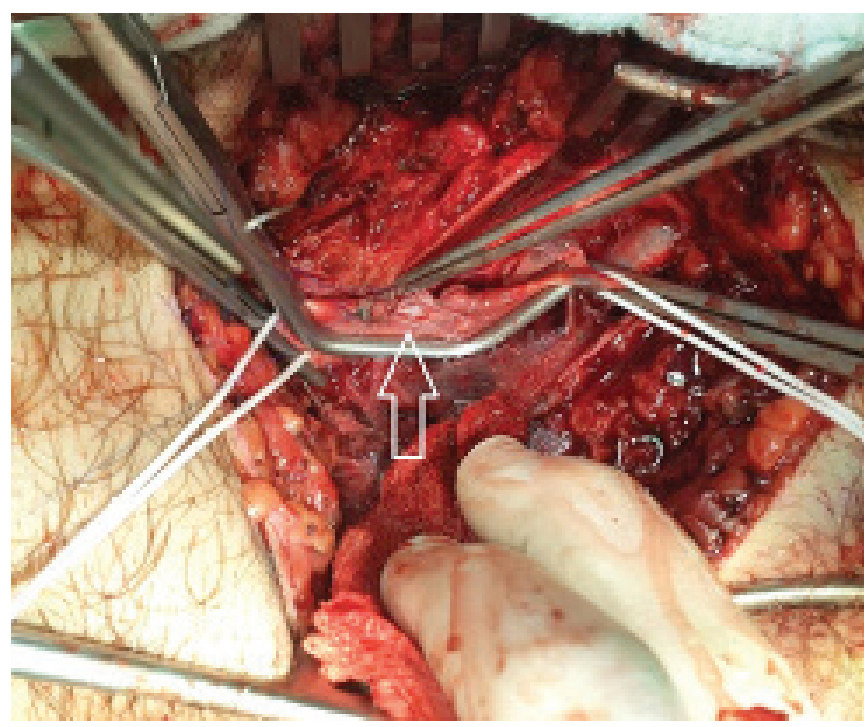

Figure 2. Arrow is showing laceration on the sideclamped common femoral vein. 
The vein was repaired primarily with lateral venorrhaphy technique (Figure 3). The venous tissue loss was not extensive, and the primary suturing gave a good result. Polypropylene 6-0 with a $13 \mathrm{~mm}$ needle was used as the suture material. The vein was then unclamped, and an intact venous refilling was observed. Erythrocyte suspensions were transfused intraoperatively to increase the hemoglobin levels. Gentamycin (160 mg/day), Cefazolin (1500 mg/day), Acetylsalicylic acid (150 mg/day) were administered during the postoperative follow-up. The patient was discharged sixth postoperative day with no further complication.

\section{Discussion}

Despite the urbanization, injuries and deaths as the result of animal attacks are still encountered all over the world. ${ }^{[7]}$ Although their rate is low compared to other usual penetrating injuries, they tend to be severe. ${ }^{[8]}$ People whose occupation is animal husbandry may be the

Figure 3. Surgical reconstruction of the common femoral vein with venorrhaphy

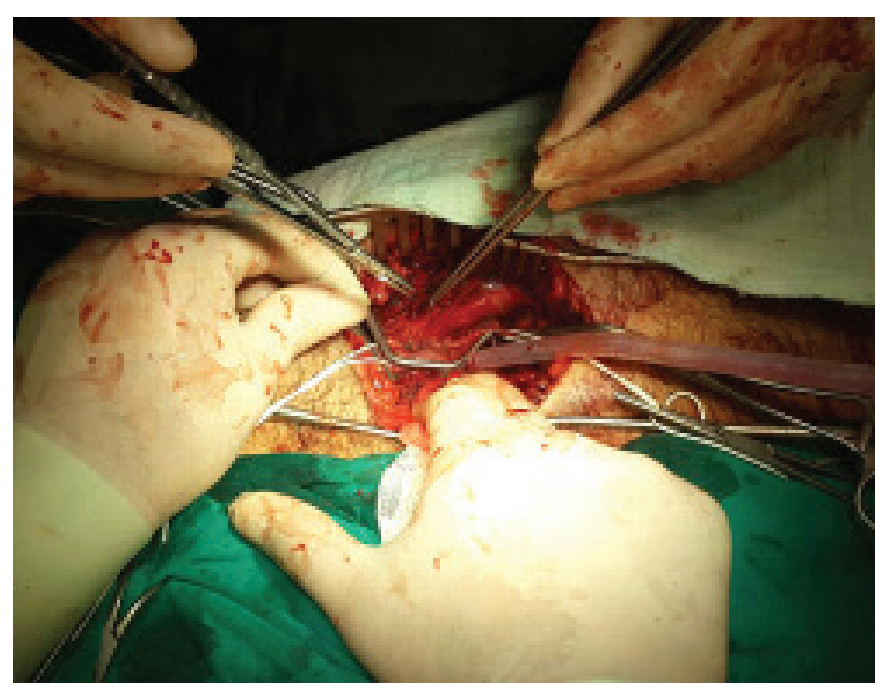

Figure 4. Patterns of bull gore injuries in different countries target of such an attack and may be severely injured or killed while tending to large animals. ${ }^{[3]}$ Apart from the farmers, other people who work with the animals including veterinarians, butchers, workers in zoos and circuses are all at high risk of bull gore. ${ }^{[9]}$ According to the studies, most of the victims of the bull attack are either the owner of the animals or workers who are responsible for their care. ${ }^{[3]}$ Bull gore injuries are common in Latin countries because these animals are frequently used in certain shows and fests. ${ }^{[10]}$ Therefore, a specialized and unique medical care for the bullfighters named Cirurgica Taurina has been established in the big arenas in Spain and South America during past two decades. ${ }^{[11]}$

The bull is normally a calm animal and may even be domesticated, but an aggressive behavior may be exhibited with no apparent reason. ${ }^{[12]}$ Bullfighting and bullrunning provoke aggressive behavior. Bullhorn injuries and its unique mechanisms have been documented in details. Understanding this mechanism of injury due to the interaction of multiple distinct forces allows handling different complex wound patterns. ${ }^{[1]}$

As the matador or victim stand in front of the attacking animal, the horn of the bull follows a semicircular path sideways and upwards. ${ }^{[13]}$ The depth of the wound is dependent on the penetration force of the bull's horn into the body and the animal's body weight and strength. ${ }^{[10]}$ The surgeon should be suspicious of underlying injuries that cannot be seen initially because of high kinetic energy transformed into the potential energy. ${ }^{[1,13]}$ In addition, the victim's body weight exerts an equal oppositional force as his body is lifted and suspended by the bull's horns. As the animal attempts to disengage the person's body, a rotational movement occurs because of an unstable balance depending on the center of gravity. This rotational movement during goring is called "rag-doll" and "spinning top" appearance..$^{[1]}$

\begin{tabular}{|l|l|l|}
\hline Country & Most common injury site & Other common injury sites \\
\hline India[14] & Perineum (36.6\%) & $\begin{array}{l}\text { Abdomen }(24.8 \%), \text { Head\&Neck (15.8\%) } \\
\text { Thorax }(13.9 \%), \text { Extremities (9.8\%) }\end{array}$ \\
\hline Turkey [3] & Abdomen $(60.9 \%)$ & Thorax $(39.1 \%)$ \\
\hline Latin Countries[1,2] & Lower extremity (>50.0\%) & Perineum (10.5\%) \\
\hline
\end{tabular}


In bull gore during bullfighting, lower leg and the thigh injuries account $50 \%$ of all wounds. ${ }^{[13]}$ Major vessels can be lacerated because of the rotational movement of the bull's head leading to a retraction in the media and intimal layers of the vasculature. This may further trigger the Virchow's triad that slows the bleeding. ${ }^{[14]}$ The second common site of goring is the perineum. Scrotal avulsion and anal destruction often need surgical reconstruction. ${ }^{[15]}$ Abdominal injuries constitute the third common injury site and have been documented most commonly on the right side.

The predominance of the right side involvement may be because of the instant reflex of the victim to turn the right side to protect himself with his right arm..$^{[1]}$ Fortunately, the intestinal damage is seen only $10 \%$ of the abdominal injury cases. ${ }^{[13]}$ However, as the pattern of injury varies in different countries, the injury site predominance also changes. For example, the perineal injuries are predominate in India while the lower extremity injuries are more common in Latin countries. ${ }^{[3,14,16]}$ This contradiction is demonstrated in Figure 4.

In the management of bull gore, precise and extensive exploration of all wounds for damage assessment under local or general anesthesia is essential. ${ }^{[1]}$ Trauma to the anus, rectum, and abdomen increase the morbidity due to fecal contamination. ${ }^{[14]}$ Bull gores directed to the femoral triangle may cause injury to the femoral sheet that contains femoral artery, femoral vein, and femoral nerve and are potentially lethal. ${ }^{[2]}$

In the case of the femoral vein injury, several surgical techniques were described according to the injury mechanism and injury site. If there is no gross tissue loss the vein can be primarily repaired. The lateral venorrhaphy is the most preferred type of primary reconstruction unless it does not result in sandglass shape of the vein. Alternative reconstruction techniques include the patchplasty, division and reanastomosis, anastomosis of the femoral vein to the deep femoral vein. ${ }^{[6]}$

In conclusion, bull gore injuries exhibit bizarre and complex wounds that require a prompt identification and exploration. Understanding the mechanism and the nature of bull gores enables the surgeon to handle adequately such atypical injuries for better outcomes. In addition to that, caution is needed for the people having close contact and working with bulls and other animals that may cause injury. The risk may be reduced by using restraints and barriers with appropriate housing and confining structures. Dehorning may also be applied as a precaution to prevent bull gore injuries. 


\section{References}

1. Lloyd MS. Matador versus taurus: bull gore injury. Ann R Coll Surg Engl 2004;86(1):3-5.

2. Rudloff U, Gonzalez V, Fernandez E, Holguin E, Rubio G, Lomelin J, et al. Chirurgica Taurina: a 10-year experience of bullfight injuries. Journal of Trauma and Acute Care Surgery 2006;61(4):970-4.

3. Dogan KH, Sunam GS, Erkol Z, Serafettin D, Zerrin E, Guven SS, et al. Injuries and deaths occurring as a result of bull attack. Journal of Agromedicine 2008;13(3):191-6.

4. Santhosh, R, Barad AK, Ghalige HS, Sridartha K, Sharma B. Perineal bull gore with urinary bladder perforation and pneumoperitoneum. Journal of Clinical and Diagnostic Research 2013;7(5):902-4.

5. Abdullah TI, Donaldson LA. An unusual case of isolated injury of the femoral vein after blunt trauma. Eur J Surg 1998;164(12):971-3.

6. Lozano FS, Estevan MC, Gónzalez-Porras JR. Femoral vein injury and transposition techniques: a new approach to venous reconstruction in the setting of trauma. J Trauma 2009;67(4):E118-20.

7. Bjornstig U, Eriksson A, Omehult L. Injuries caused by animals. Injury 1991;22(4):295-8.

8. Langley RL, Morrow WE. Deaths resulting from animal attacks in the
United States. Wilderness Environ Med 1997;8(1):8-16.

9. Wiggins P, Schenker MB, Green R, Samuels S. Prevalence of hazardous exposures in veterinary practice. Am J Ind Med 1989;16(1):55-66.

10. Ong S. Bullfighters and their wounds. World Medicine 1973;11:17.

11. Lehmann V, Lehmann J. Cirurgia Taurina-emergency medical treatment of bullfighters in Spain. Zentralbl Chir 2003;128(8):685-90.

12. Osta R, Rodellar C. Effect of genetic factors on the criteria of stress infighting bulls. Vet Res 1994;25(5):442-9.

13. Shukla HS, Mittal DK, Naithani YP. Bull horn injury: a clinical study. Injury 1977;9(2):164-7.

14. Idikula J, Moses BB. Bull horn injuries. Surg Gynaecol Obstet 1991;172(3):220-2.

15. Gonzalez-Ulloa M. Severe avulsion of the scrotum in a bullfighter: reconstructive procedure. Br J Plast Surg 1963;16:154-9.

16. Padilla Fernandez B, Diaz Alferez FJ, Garcia Garcia MA, Herrero Polo M, Velasquez Saldarriaga JF, Lorenzo Gomez MF. Bladder neck rupture following perineal bull horn injury: A surgical challenge. Clin Med Insights Case Rep 2012;5:123-8.

Received: $16 / 06 / 2017$

Accepted: 21/12/2017

Published: $15 / 03 / 2018$

Disclosure and conflicts of interest:

Conflicts of interest were not reported.

\section{Corresponding author:}

Hamit Serdar Başbuğ

Mail: s_basbug@hotmail.com 